\title{
СОПОСТАВЛЕНИЕ НЕКОТОРЫХ РАЗРЕЗОВ РАЙККЮЛАСКОГО ГОРИЗОНТА ЭСТОНИИ ПО МИКРОПЛАНКТОНУ
}

Кислотоустойчивые микрофоссилии силура Эстонии изучены сравнительно слабо (см. Мянниль, 1970; Eisenack, 1968, 1970). Р. Мянниль (1970) на основе изучения мелких серийных проб из нескольких скважин (Икла, Охесааре, Сулуствере, Кирикукюла) привел обзор распространения кислотоустойчивых микрофоссилий по горизонтам. Для райккюлаского горизонта он предлагает трехчленное деление, которого в общих чертах придерживаемся и мы.

В настоящей статье главное внимание уделяется вопросам корреляции привыходных разрезов райккюлаского горизонта, т. е. сопоставлению разрезов Средне-Эстонской структурно-фациальной зоны с разрезами Южной Эстонии. С этой целью было изучено 266 серийных проб (в основном крупных, весом $\sim 300$ 2, и значительно меньше весом $\sim 50$ 2), отобранных из кернов буровых скважин Эммасте, Варбла, Рухну, Икла, Охесааре, Кирикукюла и Сулуствере (см. рисунск). Для наглядности в тексте и на рисунке приводятся только наиболее характерные для райккюлаского горизонта виды хитинозой и акритарх. Виды, проходящие горизонт полностью или встречающиеся единичными экземплярами, здесь не рассматриваются. Литостратиграфическое расчленение разрезов дается по Э. Юргенсон (1966), Д. Кальо и П. Вингисаару (1969), Д. Кальо (1970), а также по неопубликованным материалам Р. Эйнасто и Э. Кала.

Автор признателен Р. Мяннилю за полезные советы и предоставление готовых препаратов, Э. Кала и Р. Эйнасто за возможность использования литологической колонки всех разрезов, лаборантам Института геологии АН ЭССР Х. Партс и Д. Марк за- помощь, оказанную при обработке проб.

Нижняя граница райккюлаского горизонта, принятая Х. Нестором и Э. Кала (1968), хорошо совпадает с зонами микропланктона. Она отмечается массовым появлением Conochitina sp. n. и, несколько выше по разрезу, Cyathochitina calix, в то время как для верхов юуруского горизонта характерны виды Conochitina micracantha, Cyathochitina campanulaeformis, C. kuckersiana и Goniosphaeridium oligospinosum. Исключение составляет разрез скв. Охесааре, где в самых низах райккюлаского горизонта Conochitina sp. n. не встречается (выше по разрезу распространяется с перерывами), а присутствует Cyathochitina campanulaeformis (инт. $405,2-410,0$ м). Однако наличие этого вида не препятствует включению названного интервала в состав райккюлаского горизонта, так как в отдельных пробах из скв. Рухну, Варбла, Сулуствере Cyathochitina cam- 
panulaeformis обнаружен на том же стратиграфическом уровне (см. рисунок). Отсутствие других характерных для юуруского горизонта видов (Conochitina micracantha и Goniosphaeridium oligospinosum) позволяет включить эту часть разреза Охесааре в состав нижних слоев райккюлаского горизонта.

Райккюлаский горизонт наиболее полно представлен в скв. Икла (инт. $322,7-494,0$ м). Этот разрез принят за типовой для всех трех рассматриваемых здесь подразделений райккюлаского горизонта, выделенных по микропланктону (снизу вверх).

\section{Слои с Cyathochitina и Conochitina sp. n. $\left(\mathrm{G}_{3}^{\mathrm{I}}\right)$}

В типовом разрезе скв. Икла эти слои выделяются в интервале 469,7 494,0 м. Наибольшую мощность они имеют в Восточной Эстонии (Сулуствере - 33 м) и наименьшую - в Северо-Западной (Эммасте - 18,4 м). Нижняя граница слоев проводится нами, согласно Р. Мяннилю (1970), по массовому появлению Conochitina sp. n. (=Conochitina aff. elegans; Мянниль, 1970) и Cyathochitina. Р. Мянниль (1970) при определении верхней границы руководствовался появлением Coronochitina sp. n., которые прослеживаются в разрезе ниже того уровня, где исчезают Conochitina sp. n. и Cyathochitina. Однако отсутствие Coronochitina sp. n. в северных разрезах (при выдержанности остального видового комплекса) побудило нас выбрать для установления верхней границы иной критерий, а именно исчезновение в слоях Conochitina sp. п. и Cyathochitina.

Описываемые слои представлены в двух интервалах $\left(\mathrm{G}_{3}^{\mathrm{Ia}}, \mathrm{G}_{3}^{\mathrm{Ic}}\right)$, раз. деленных слоями, почти лишенными микрофоссилий $\left(\mathrm{G}_{3}^{\mathrm{Ib}}\right)$. Для нижнего интервала $\left(\mathrm{G}_{3}^{\mathrm{Ia}}\right)$ характерны Conochitina sp. п. и Cyathochitina calix, для верхнего $\left(\mathrm{G}_{3}^{\mathrm{Ic}}\right.$ ) - Conochitina sp. п. и Cyathochitina kuckersiana. Из них Conochitina sp. n. распределен здесь обильно и равномерно, кроме скв. Oхесааре, о чем было упомянуто выше. В распространении Суаthochitina можно отметить некоторые, возможно фациальные, особенности. В слоях скв. Икла Cyathochitina calix встречается вместе с многочисленными граптолитами; в отдельных пробах из разрезов скв. Рухну, Варбла и Охесааре ему сопутствует Cyathochitina campanulaeformis; последний вид установлен в скв. Сулуствере лишь в некоторых пробах и в незначительном количестве; в скв. Кирикукюла Cyathochitina не обнаружен (причина, возможно, в малом весе проб). В скв. Эммасте Cyathochitina campanulaeformis встречается вместе с Cyathochitina kuckersiana, причем из-за наличия переходных форм бывает трудно точно идентифицировать все экземпляры и даже популяции.

Как уже отмечалось выше, в верхах слоев $\mathrm{G}_{3}^{\mathrm{Ia}}$ в юго-западных разрезах (скв. Икла, Рухну, Охесааре) появляется Coronochitina sp. n. В некоторых разрезах (Икла, Варбла) в верхах слоев $\mathrm{G}_{3}^{\text {Ic }}$ попадаются единичные экземпляры Conochitina cf. edjelensis - вида, характерного для слоев $\mathrm{G}_{3}^{\mathrm{III}}$.

На фоне распределения названных видов обращает на себя внимание ритмичность изменения соотношений планктона и бентоса в ассоциациях кислотоустойчивых микрофоссилий и численности последних. Интервалы, богатые планктоном, чередуются с интервалами, где его количество резко убывает, но зато появляются различные бентосные элементы. Так, в пределах слоев $\mathrm{G}_{3}^{\mathrm{Ia}}$ во всех разрезах (кроме скв. Варбла, судить о которой не позволяет малая частота опробования) можно различить четыре интервала с обильным и три - с обедненным планктоном. Исключение 


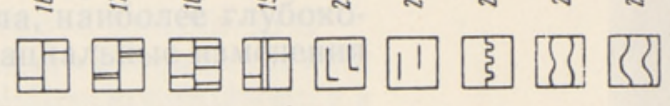

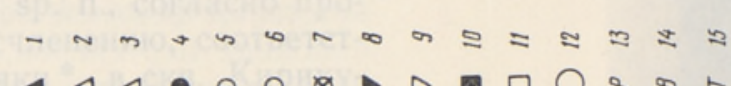

$\triangleleft \triangleleft \triangleleft \bullet \bullet ० \otimes \triangleright D$ प

舁

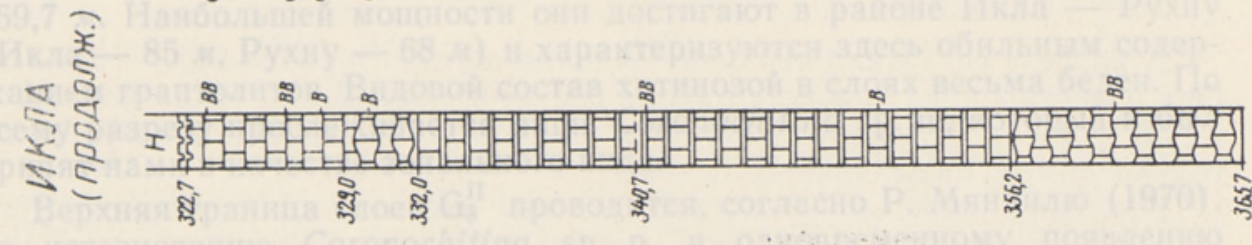
$\infty$

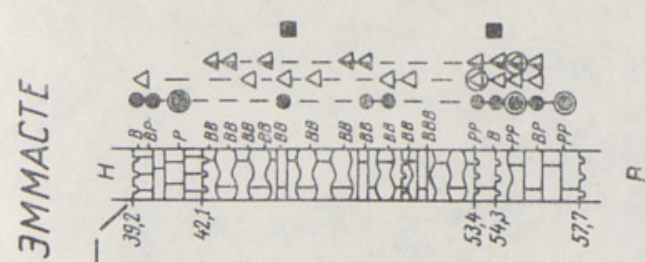

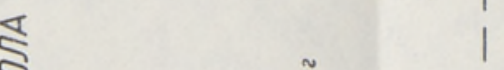

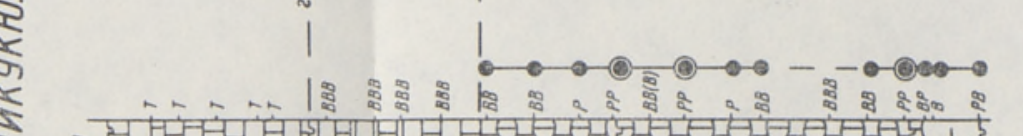

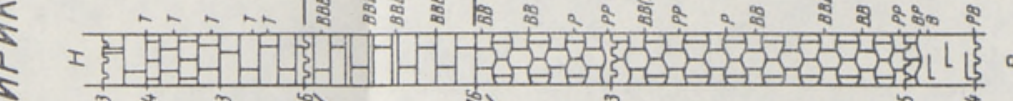

岕

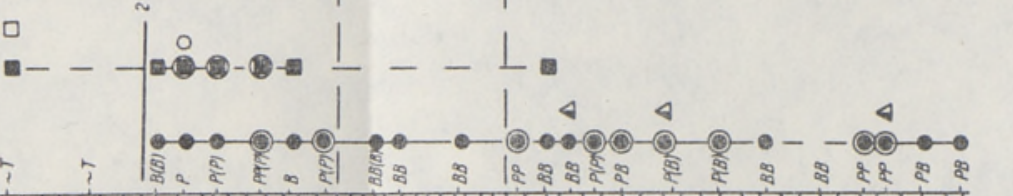
(1)

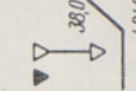

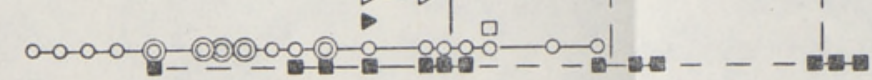

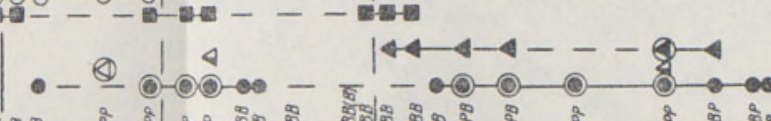

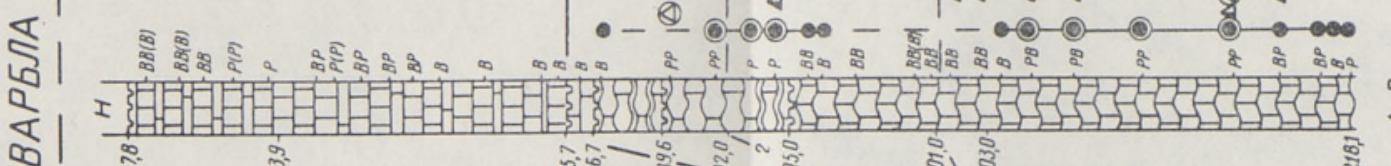

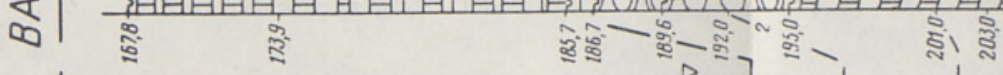

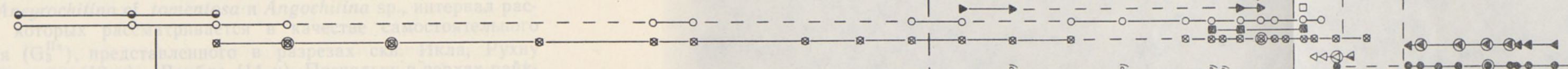

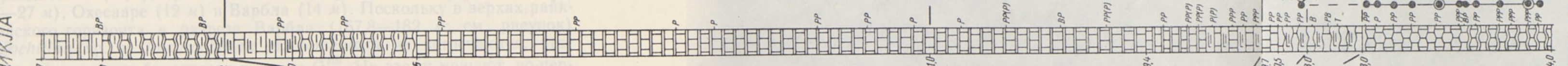
电

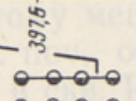

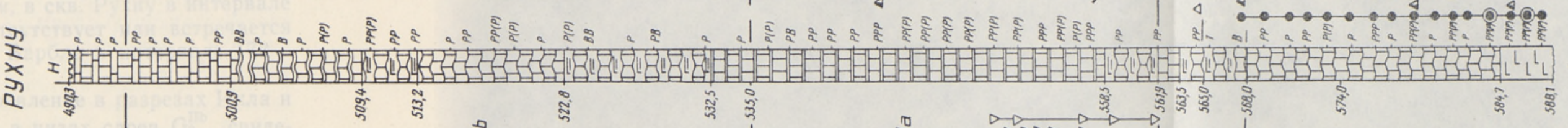

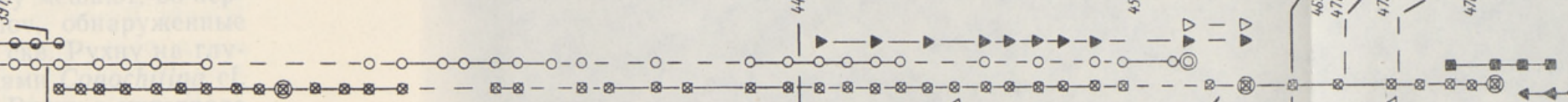

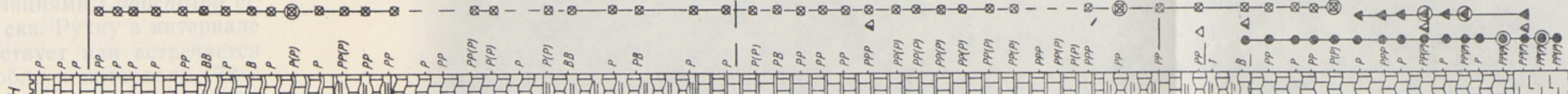
囦

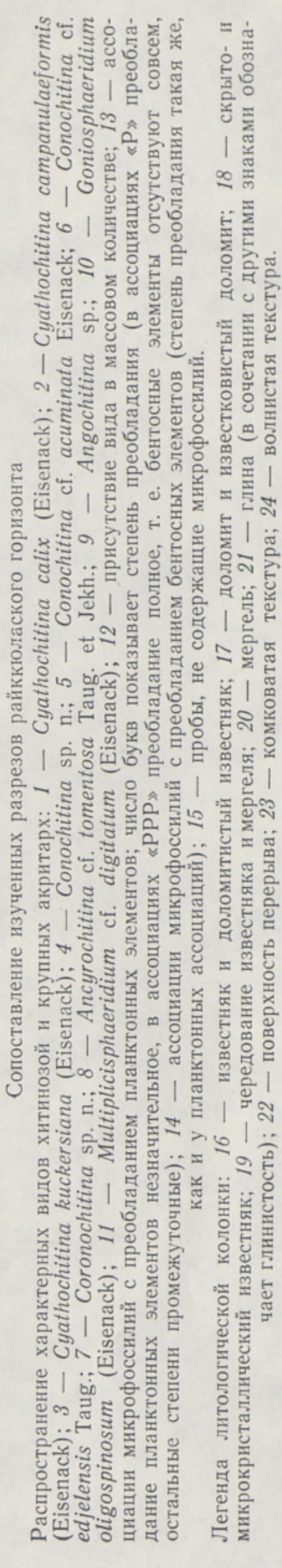




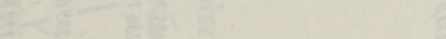


составляет разрез скв. Икла, где на том же уровне выделяются два интервала с массовым распространением планктона и промежуточный интервал с повышенным содержанием микробентоса. Можно предполагать, что такая невыдержанность является результатом каких-то ритмичных изменений фациальных условий бассейна. В районе Икла, наиболее глубоководной части изучаемой территории, эти скрытые фациальные изменения проявлялись не так четко.

В скв. Икла слои с Cyathochitina и Conochitina sp. n., согласно проведенному Д. Кальо и П. Вингисааром (1969) расчленению, соответствуют стуриской пачке и нижней части ремтской пачки *, в скв. Кирикукюла и Сулуствере - вингутаской пачке (по Э. Юргенсон (1966)), а в скв. Охесааре - мергелевой пачке (по Кальо (ред.), 1970). На приблизительную одновозрастность нижней границы райккюлаского горизонта в скважинах Северной Эстонии и в скв. Икла указывал, руководствуясь отдельными находками граптолитов, и Д. Кальо (1969).

\section{Слои с Coronochitina sp. n. $\left(\mathrm{G}_{3}^{\mathrm{II}}\right)$}

В типовом разрезе скв. Икла эти слои приходятся на интервал $381,2-$ 469,7 м. Наибольшей мощности они достигают в районе Икла - Рухну (Икла - 85 м, Рухну - 68 м) и характеризуются здесь обильным содержанием граптолитов. Видовой состав хитинозой в слоях весьма беден. По всему разрезу прослеживается лишь Coronochitina sp. n., который и был принят нами в качестве зонального вида.

Верхняя граница слоев $\mathrm{G}_{3}^{\text {II }}$ проводится, согласно Р. Мяннилю (1970), по исчезновению Coronochitina sp. п. и одновременному появлению Conochitina cf. acuminata. В низах слоев вместе с Coronochitina sp. n. встречаются Ancyrochitina cf. tomentosa и Angochitina sp., интервал распространения которых рассматривается в качестве самостоятельного подразделения $\left(\mathrm{G}_{3}^{\mathrm{IIa}}\right)$, представленного в разрезах скв. Икла, Рухну $(26-27 \mu)$, Охесааре $(12 \mu)$ и Варбла $(14 \mu)$. Поскольку в верхах райккюлаского горизонта в разрезе Варбла (167,8-182 Angochitina sp. и Ancyrochitina cf. tomentosa не встречаются, этот интервал следовало бы отнести к слоям $\mathrm{G}_{3}^{\mathrm{IIb}}$. Но этому мешают, во-первых, находки очень редких Foraminifera gen. et sp. nov., обнаруженные только в разрезе скв. Варбла на глубине 177,3 м и в скв. Рухну на глубине 556,5 м, и, во-вторых, сходство между популяциями Conochitina cf. edjelensis в скв. Икла в интервале $450-458$ м, в скв. Рухну в интервале 552-558 м (где Coronochitina sp. п. или отсутствует или встречается только единичными экземплярами) и в скв. Варбла в интервале 172$178 \mathrm{M}$.

Учитывая приведенные факты, а также появление в разрезах Икла и Рухну многочисленных бентосных элементов в низах слоев $\mathrm{G}_{3}^{\mathrm{Ib}}$, свидетельствующее о регрессии моря, более вероятно, что в скв. Варбла представлен не весь разрез $\mathrm{G}_{3}^{\mathrm{II}}$, а главным образом его нижняя часть $\left(\mathrm{G}_{3}^{\mathrm{IIa}}\right)$.

В скв. Сулуствере на том же стратиграфическом уровне над слоями $\mathrm{G}_{3}^{\mathrm{I}}$ залегают слои (инт. 32-38 м), почти лишенные кислотоустойчивых микрофоссилий. Здесь встречаются лишь редкие Goniosphaeridium oligospinosum и Multiplicisphaeridium cf. digitatum. Те же виды установлены в скв. Варбла и Икла вместе с видовым комплексом хитинозой из слоев с

* По предложенню Р. Ульста (1973) отложения на севере Латвии и юге Эстонии, ранее относимые к ремтской пачке, выделяются теперь в качестве колкской. 
Coronochitina sp. n. На основании этого данную часть разреза Сулуствере следует считать возрастным аналогом нижних слоев с Coronochitina sp. n. В скв. Кирикукюла предполагаемые возрастные аналоги упомянутых слоев уже не содержат микрофоссилий.

В остальной, верхней части слоев $\left(\mathrm{G}_{3}^{\text {Ilb }}\right)$, развитой только в скв. Икла и Рухну, широко представлены лишь многочисленные Coronochitina sp. n. и Conochitina cf. edjelensis. В скв. Икла слои с Coronochitina sp. n. соогветствуют верхней половине ремтской пачки, иклаской пачке и нижней половине мергелевой пачки (Кальо, Вингисаар, 1969). Так как отмеченный выше интервал над слоями $\mathrm{G}_{3}^{\mathrm{I}}$ в скв. Сулуствере и Кирикукюла был отнесен к кулламааской (Юргенсон, 1966), а в скв. Икла - к верхней половине ремтской пачки, можно предполагать, что эти пачки одновозрастны, по крайней мере в рассматриваемых разрезах.

В скв. Охесааре, Варбла, Сулуствере и Кирикукюла разрез райккюлаского горизонта заканчивается, по всей вероятности, нижней частью слоев с Coronochitina $\left(\mathrm{G}_{3}^{\text {IIa }}\right)$, выше которой наблюдается седиментационный перерыв до начала адавереского времени.

\section{Слои с Conochitina cf. edjelensis ( $\left.\mathrm{G}_{3}^{\mathrm{III}}\right)$}

В разрезе скв. Икла эти слои выделяются в интервале $322,7-381,2$ м. Они известны пока только в районе Икла-Рухну. В скв. Икла мощность их 58 м, в скв. Рухну - около 4 м, причем в последней представлены только самые низы данных слоев.

Критерии проведення нижней границы указаны выше. Верхняя граница райккюлаского горизонта маркируется появлением новых форм микропланктона - Estiastra magna, Conochitina sp. n. 2 и других, а также исчезновением (хотя уже в низах адавереского горизонта) Conochitina cf. edjelensis.

Слои с Conochitina cf. edjelensis (=Conochitina aff. pachycephala; Мянниль, 1970) характеризуются бедным содержанием и однородным составом микропланктона. В нижней части слоев, соответствующей верхней половине мергелевой пачки в скв. Икла и их аналогам в скв. Рухну, кроме Conochitina cf. edjelensis, встречается только Conochitina cf. acuminata. Выше по разрезу, в самой верхней части райккюлаского горизонта, роль микропланктона уменьшается еще заметнее. Даже находки Conochitina cf. edjelensis весьма немногочисленны.

Д. Кальо и П. Вингисаар (1969) отнесли часть разреза скв. Икла, соответствующую слоям с Conochitina $\mathrm{cf}$. edjelensis, к верхам мергелевой пачки и к вингутаской пачке.

\section{Заключение}

Корреляция отложений райккюлаского горизонта по распределению хитинозой и крупных акритарх показывает, что наиболее широко развиты его нижние слои $\left(\mathrm{G}_{3}^{1}\right)$, сложенные в Северной и Средней Эстонии комковатыми микро- и скрытокристаллическими известняками вингутаской пачки и в Южной Әстонии - известняками стуриской пачки.

В наиболее северных разрезах четко выделяется лишь нижняя половина слоев с Conochitina sp. n. и Cyathochitina $\left(\mathrm{G}_{3}^{\text {Ia }}\right)$, верхняя же, вероятно, или отсутствует (скв. Эммасте), или представлена слоями, не содержащими микропланктона (скв. Кирикукюла).

Средние слои райккюлаского горизонта распространены на значительно меньшей территории. Выше отмечалось, что в слоях с Coronochi- 
tina sp. n., особенно в их нижней части, в ассоциациях кислотоустойчивых микрофоссилий преобладают планктонные элементы (хитинозои, сикулы граптолитов и др.). С исчезновением из разреза Coronochitina sp. n. в середине мергелевой пачки скв. Икла планктонная ассоциация резко обедняется. Эта тенденция вверх по разрезу усугубляется: в средней и верхней части слоев с Conochitina cf. edjelensis $\left(\mathrm{G}_{3}^{\mathrm{IIIb}}\right)$ перевес бентосных элементов (меланосклеритов, фораминифер, сколекодонтов и др.) уже значителен. Вероятно, эти изменения в ассоциациях микрофоссилий связаны с регрессией моря.

Верхи райккюлаского горизонта $\left(\mathrm{G}_{3}^{\mathrm{III}}\right)$ развиты только в самой южной части Эстонии (скв. Икла, Рухну). Этой части разреза в других местах соответствует, вероятно, перерыв в осадконакоплении, продолжавшийся до ранее установленной трансгрессии адавереского времени (Кальо (ред.), 1970; Эйнасто и др., 1972; Нестор, 1972).

Разновозрастные слои райккюлаского горизонта $\left(\mathrm{G}_{3}^{\mathrm{I}}-\mathrm{G}_{3}^{\mathrm{III}}\right)$ покрыты трансгрессивно залегающим адавереским горизонтом с характерным комплексом микрофоссилий (Estiastra magna, Conochitina sp. n. 2, Conochitina sp. n. 3 и др.). Как установлено Р. Мяннилем, в самой юго-западной части Эстонии (скв. Охесааре) пентамеровые слои адавереского горизонта также отсутствуют, что объясняется седиментационным перерывом (Мянниль, 1970; Эйнасто и др., 1972). Соответствующая часть разреза в скв. Рухну представлена слоями мощностью только около $1 \mathrm{~m}$.

Таким образом, сопоставление разрезов по кислотоустойчивым микрофоссилиям подтверждает общее представление о регрессивном характере разреза райккюлаского горизонта Әстонии (Кальо, 1970; Эйнасто и др., 1972) и одновременно показывает, что стратиграфический перерыв между райккюласким и адавереским горизонтами в привыходном районе более значителен, чем предполагалось до сих пор.

\section{Л И Т Е Р А Т Р А}

Кальо Д. 1970. Райккюлаский горизонт. В кн.: Силур Эстонии (ред. Кальо). Таллин. Кальо Д., В и нги са а р П. 1969. О разрезе райккюлаского горизонта на южной окраине Эстонии. Изв. АН ЭССР. Хим. Геол., 18, № 3.

М янни ль Р. М. 1970. Кислотоустойчивые микрофоссилии. В кн.: Силур Эстонии (ред. Кальо). Таллин.

Н е с т о Р Х. 1972. О возрастном диапазоне слоев с Pentamerus oblongus и о характере позднелландоверийской трансгрессии в Северной Европе. Изв. АН ЭССР. Хим. Геол., 21 , № 4.

Н ест ор Х., Кала Э. 1968. Ревизия стратиграфии низов силура Северной Прибалтики. В сб.: Стратиграфия нижнего палеозоя Прибалтики и корреляция с другими регионами. Вильнюс.

Ульст Р. 1973. Лландоверийские отложения Северной Латвии и их корреляция. В кн.: Проблемы региональной геологии Прибалтики и Белоруссии. Рига.

Э й н а с т о Р., Н е с т о р Х., К а л а Э., К а я к К. 1972. Сопоставление верхнелландоверийских разрезов в Западной Эстонии. Изв. АН ЭССР. Хим. Геол., 21, № 4.

Юрген сон Э. А. 1966. Литология лландоверийских отложений Эстонии. Таллин.

E is en a ck A. 1968. Ober Chitinozoen des baltischen Gebietes. Palaeontographica, Abt. A, 131, Nr. 5-6.

E isenack A. 1970. Mikrofossilien aus dem Silur Estlands und Insel Osel. Geol. Fören. i Stockholm Förhandl., 92. 
Viiu NESTOR

\section{MÕNINGATE EESTI RAIKKULA LADEME LÄBILÖIGETE KÕRUTAMINE MIKROPLANKTONI ALUSEL}

Mikroplanktoni, põhiliselt kitinosoade esinemise alusel on võrreldud Põhja-Eesti struktuurilis-fatsiaalse vööndi raikküla lademe läbilōikeid (Emmaste, Kirikuküla, Varbla, Sulustvere) Lõuna-Eesti läbilõigetega (Ikla, Ruhnu, Ohesaare). On eristatud 3 tsooni koos alamtsoonidega ning antud nende iseloomustus. Uuritud alal on kōige ulatuslikumad raikküla lademe alumised kihid $\left(\mathrm{G}_{3}^{\mathrm{I}}\right)$, kusjuures vinguta kihistik Pōhja-Eestis on ühevanune sturi kihistikuga Lōuna-Eestis. Lademe keskmiste kihtide $\left(\mathrm{G}_{3}^{\mathrm{II}}\right)$ ulatus on tunduvalt väiksem, ülemised kihid $\left(\mathrm{G}_{3}^{\mathrm{III}}\right)$ on aga kindlaks tehtud ainult LõunaEestis (Ikla, Ruhnu). Mujal vastab läbilõike sellele osale tõenäoliselt settelünk.

Viiu NESTOR

\section{A MICROPLANKTON CORRELATION OF BORING SECTIONS OF THE RAIKKULA STAGE, ESTONIA}

The distribution of chitinozoans (and some large acritarchs) in the rocks of the Middle Llandoverian Raikküla Stage has allowed to correlate several core sections of the stage of Middle Estonia (Emmaste, Kirikuküla, Varbla and Sulustvere) with those of South Estonia (Ikla, Ruhnu and Ohesaare sections). Three zonation units and five subunits have been distinguished in the sequence of the stage. They are characterized in the present paper.

Differences in the distribution of various Cyathochitina species in the lowermost part of the Raikküla Stage are discussed. They are obviously due to varying facial conditions.

The rhythmical changes in the abundance of acid-resistant microfossils, connected with the mutual changes in planktonic and benthic elements are considered. As those rhythmical changes can be correlated; they are connected with the rhythmical changes in the sedimentation within the basin.

The synchronism of the Vinguta Member in Middle Estonia and the Sturi Member in South Estonia is established, while the synchronism of the Remte and Kullamaa Members is assumed.

It is shown that in the studied area the lower part of the Raikküla Stage $\left(\mathrm{G}_{3} \mathrm{I}\right)$ is of the widest distribution, whereas the middle part $\left(\mathrm{G}_{3}{ }^{\mathrm{II}}\right)$ is much more limited. Thus, the Ohesaare, Varbla, Sulustvere and Kirikuküla sections obviously represent only the lower part of the named layers. The upper part of the stage $\left(\mathrm{G}_{3}{ }^{\mathrm{III}}\right)$ has been identified only in South Estonia (Ikla and Ruhnu sections), elsewhere it seems to correspond to a hiatus which lasted up to the well-known transgression of the Adavere age. Consequently, the distribution of acid-resistant microfossils testifies to the earlier data about the regressive nature of the Raikküla Stage. At the same time, this proves that the stratigraphic hiatus between the Raikküla and Adavere Stages in the outcrop area is much wider than previously assumed.

The distribution of selected chitinozoan and large acritarch species most characteristic of the Raikküla Stage within the studied sequences is presented in the text-figure (1-11, see the Russian text on page). Legend for other signs: 12 - abundant occurrence of a species in the sample; 13 - microfossil associations with planktonic elements prevailing. The number of letters stands for the stage of prevalence (PPP means the absence of benthic elements in the sample); $14-$ microfossil associations with benthic elements prevailing. The number of letters stands for the stage of prevalence (BBB means the absence of planktonic elements in the sample); 15 samples yielding no acid-resistant microfossils; 16 - limestone and dolomitic limestone; 17 - dolomite and calcitic dolomite; 18 - micro- and crypto-crystalline limestone; 19 - intercalation of limestone and marl; 20 - marl; 21 - clay (when with other signs, stands for the clay content); 22 - discontinuity surface; 23 - nodular structure; 24 - wavy-layered structure. 